\title{
Genderwise Investigation of Empahty Skills in Child Athletes
}

\section{Yasin ARSLAN1', Gülfem SEZEN-BALÇIKANLI²}

\author{
${ }^{1}$ Tokat Gaziosmanpaşa University, School of Physical Education and Sport, Tokat, Turkey \\ ${ }^{2}$ Gazi University, Faculty of Sports Sciences, Ankara, Turkey \\ Address Correspondence to Y. Arslan, e-mail: arslan@gazi.edu.tr
}

\begin{abstract}
This study intends to investigate the empathy skills in child athletes with regard to gender. The study group comprises 226 children selected randomly from various clubs in Ankara. $56.7 \%$ of the total number is female and $40.3 \%$ is male. When the sports age of the group with a mean age of 12.16 is examined, it can be seen that $40.7 \%$ have been doing sports for $1-2$ years, $42.0 \%$ have been doing sports for 3-4 years and $17.3 \%$ have been doing sports for 5-6 years. The study group is distributed into branches, with $29.2 \%$ pertaining to volleyball, $42 \%$ to handball, and $28.8 \%$ to basketball. In the study, 'Empathy Scale for Children' developed by Bryant (3) and adapted to Turkish by Yüksel (23) was used as data collection tool. The frequency, percentage distributions and the mean values of the sub-dimensions of the scales were calculated. Independent Samples Ttest was used to determine the empathy levels of the child athletes. When the findings were examined, it was seen that the empathy levels of the child athletes differed according to gender and this difference was statistically significant in favor of girls $(\mathrm{p}=.00)$. As a result, the activities aiming to improve the sportspeople's taking roles and perspectives along with empathetic thinking skills should be included in the process of creating empathetic people thus empathetic sensitivity should be increased.
\end{abstract}

Keywords: Children, Child athletes, Empathy, Gender, Sports

\section{INTRODUCTION}

Empathy is a concept that we use widely in human relationships and interactions. Affecting many positive behaviors of people such as morality, prosocial behaviors, understanding and quality communication, empathy is a skill that is being researched and tried to be developed. Usually studied in adults, empathy should be gained at an early age.

When the definitions of empathy are examined in the literature, it is seen that different dimensions of empathy have been emphasized. However, the most commonly agreed issue is that empathy is a multidimensional structure (5), which defines empathy as the reaction of one person to another's observed experiences. According to Davis, empathy has both affective and cognitive elements (5). According to the definition of Rogers who characterizes empathy as a process, it is the process whereby people take their counterpart's perspective by putting themselves in his or her position, understand and feel that person's feelings and thoughts correctly and communicate this state to him or her (13).

Empathy is known to have very clear positive results. The results are always the same for a wide range of people from a schizophrenic patient to students in a regular classroom, from counselors in a counseling center to teachers in education, from German neuroscientists to American neuroscientists. These results show that being sensitive as a Turk ل Sport Exe 2019; 21(2): 234-237 ๑ 2019 Faculty of Sport Sciences, Selcuk University consultant or teacher is closely related to the formation of constructivist learning and change. Empathy is defined as a skill and thought to be gained through education. From this point, parents and teachers can help children become empathetic people (13). Kohlberg states that the ability to take another person's role has started to develop from the age of six, and the development of this ability is a turning point in the development of moral ability because moral judgment is the individual's weighing the rights of others against their own rights, which necessitates the ability to take roles (1).

When the factors affecting empathy skills are examined, it is seen that sport is also among these factors. In particular, the interactions in team sports are built on coordinating the game, which requires the ability to understand the game. Sportspeople need to anticipate which behaviors each individual team member might exhibit in different situations, which allows them to improve their perspectives. While it is possible to talk about empathy education that can be gained through sports, it is seen in the literature that especially the competition-oriented sports environment reduces empathy (22). However, the studies on the relationship between sports and empathy, especially with children, appear to be inadequate $(6,12,19,17,14,18,15)$. Although empathy has positive effects on many issues such as solidarity, morality, 
prosocial behaviors, and healthy communication, it is thought that there is a negative relationship between empathy and competition. When the literature is examined, it is understood that children, sports and empathy triangle do not have available information and the relationship between sports and empathy in children arouses curiosity. From this point of view, the aim of the study is to determine the empathy levels of child athletes and examine them in terms of gender.

\section{MATERIAL \& METHOD}

\section{Study Group}

The study group comprises children selected randomly from various clubs in Ankara. With $56.7 \%$ of the group being female and $40.3 \%$ male, the total number of child athletes in the study are 226. The group's mean age is 12.16 . When the sports age of the group is examined, it is seen that $40.7 \%$ have been doing sports for 1-2 years, $42.0 \%$ have been doing sports for 3-4 years and $17.3 \%$ have been doing sports for 5-6 years. The distribution of the sportspeople by branch is as follows: $29.2 \%$ volleyball, $42.0 \%$ handball, and $28.8 \%$ basketball (Table 1).

After checking the scales collected by the researchers, the missing or incorrect ones were excluded from the research. The valid and acceptable ones were transferred to the computer for evaluation in SPSS package program. The

\section{FINDINGS}

\begin{tabular}{|c|c|c|}
\hline Variables & & $\%$ \\
\hline \multirow{2}{*}{ Gender } & Female & 59.7 \\
\hline & Male & 40.3 \\
\hline Age & & $\mathrm{M}=12.16$ \\
\hline \multirow{3}{*}{ Sports Branch } & Volleyball & 29.2 \\
\hline & Handball & 42.0 \\
\hline & Basketball & 28.8 \\
\hline \multirow{3}{*}{ Sports Age } & 1-2 yrs. & 40.7 \\
\hline & 3-4 yrs. & 42.0 \\
\hline & 5-6 yrs. & 17.3 \\
\hline
\end{tabular}

According to the data in Table 1, 59.7\% of the child athletes are female and $40.3 \%$ are male with a mean age of 12.16. When the sports branches are examined, it is seen that $29.2 \%$ belong to volleyball branch, $42 \%$ to handball and

\section{Data Collection Tool}

In this study, 'Empathy Scale for Children' was used to determine the empathy levels of children.

\section{Empathy Scale for Children}

The Empathy Scale for Children was developed by Bryant (3). As a result of the adaptation study conducted by Yüksel (23), the Turkish version of the scale, which was originally 22 items, had 20 items and a single factor structure. The Empathy Scale for Children was calculated by repeating the test and its reliability coefficient was $r=$ .69. The internal consistency (Cronbach Alpha) coefficient of the scale was found to be .70. Items were marked as True or False (i.e. I get upset when I see a girl who can't find friends to play with; I cannot understand people in society who show their joy by hugging each other). A higher score from the scale reflects more empathy.

\section{Data Analysis}

frequency, percentage distributions and mean values of the sub-dimensions of the scales were calculated. Independent Samples T-test was used to determine the empathy levels of the sport people.

\begin{tabular}{|c|c|c|c|c|c|c|c|}
\hline \multicolumn{8}{|c|}{ FEMALE $(\mathrm{N}=135)$} \\
\hline Items & Response & $\%$ & $\mathrm{M}$ & SD & $\%$ & $\mathrm{M}$ & S.D \\
\hline \multirow{2}{*}{ 1- I get upset when I see girl crying to play. } & True & 91.9 & \multirow{2}{*}{.92} & \multirow{2}{*}{.27} & 57.1 & \multirow{2}{*}{.57} & \multirow{2}{*}{.50} \\
\hline & False & 8.1 & & & 42.9 & & \\
\hline \multirow{2}{*}{$\begin{array}{l}\text { 2- I cannot understand people who show their } \\
\text { joy by hugging each other in public. }\end{array}$} & True & 86.7 & \multirow{2}{*}{.87} & \multirow{2}{*}{.34} & 75.8 & \multirow{2}{*}{.76} & \multirow{2}{*}{.43} \\
\hline & False & 13.3 & & & 24.2 & & \\
\hline \multirow{2}{*}{$\begin{array}{l}\text { 3- I cannot understand a boy crying when he is } \\
\text { happy. }\end{array}$} & True & 63.0 & \multirow{2}{*}{.63} & \multirow{2}{*}{.48} & 38.5 & \multirow{2}{*}{.38} & \multirow{2}{*}{.49} \\
\hline & False & 37.0 & & & 61.5 & & \\
\hline \multirow{2}{*}{$\begin{array}{l}\text { 4- It pleases me to watch a friend open a gift } \\
\text { package at his/her birthday party. }\end{array}$} & True & 85.2 & \multirow{2}{*}{.85} & \multirow{2}{*}{.36} & 68.1 & \multirow{2}{*}{.68} & \multirow{2}{*}{.47} \\
\hline & False & 14.8 & & & 31.9 & & \\
\hline
\end{tabular}
sports people, $40.7 \%$ have 1-2 years, $42 \%$ have $3-4$ years and $17.3 \%$ have $5-6$ years of sports experience. 


\begin{tabular}{|c|c|c|c|c|c|c|c|}
\hline 5- When I see a boy crying, I get watery eyes. & $\begin{array}{l}\text { True } \\
\text { False }\end{array}$ & $\begin{array}{l}43.7 \\
56.3\end{array}$ & .44 & .50 & $\begin{array}{l}44.0 \\
56.0\end{array}$ & .44 & .50 \\
\hline \multirow{2}{*}{$\begin{array}{l}\text { 6- I get watery eyes when I see a girl fall and } \\
\text { injure herself while playing. }\end{array}$} & True & 73.3 & \multirow{2}{*}{.73} & \multirow{2}{*}{.44} & 25.3 & \multirow[b]{2}{*}{.25} & \multirow{2}{*}{.44} \\
\hline & False & 26.7 & & & 74.7 & & \\
\hline \multirow{2}{*}{ 7- I sometimes cry when I watch TV. } & True & 48.9 & \multirow{2}{*}{.49} & \multirow{2}{*}{.50} & 24.2 & \multirow{2}{*}{.24} & \multirow{2}{*}{.43} \\
\hline & False & 51.1 & & & 75.8 & & \\
\hline \multirow{2}{*}{$\begin{array}{l}\text { 8- I cannot understand a girl crying when she } \\
\text { is happy. }\end{array}$} & True & 74.8 & \multirow{2}{*}{.75} & \multirow{2}{*}{.44} & 36.3 & \multirow{2}{*}{.36} & \multirow{2}{*}{.48} \\
\hline & False & 25.2 & & & 63.7 & & \\
\hline \multirow{2}{*}{$\begin{array}{l}\text { 9- I get very sad when I see an animal being } \\
\text { harmed. }\end{array}$} & True & 96.3 & \multirow{2}{*}{.96} & \multirow{2}{*}{.19} & 93.4 & \multirow{2}{*}{.93} & \multirow{2}{*}{.25} \\
\hline & False & 3.7 & & & 6.6 & & \\
\hline \multirow{2}{*}{$\begin{array}{l}\text { 10- I get upset when I see a boy who can't find } \\
\text { friends to play with. }\end{array}$} & True & 58.5 & \multirow{2}{*}{.59} & \multirow{2}{*}{.49} & 70.3 & \multirow{2}{*}{.70} & \multirow{2}{*}{.46} \\
\hline & False & 41.5 & & & 29.7 & & \\
\hline 11- My eyes fill with tears when I listen to & True & 65.9 & & & 31.9 & & \\
\hline some songs. & False & 34.1 & .66 & .48 & 68.1 & .32 & .47 \\
\hline 12- I feel like crying when I see a boy hurt & True & 31.9 & .32 & .47 & 28.6 & .29 & .45 \\
\hline himself while playing. & False & 68.1 & .32 & $.4 /$ & 71.4 & .29 & .4 \\
\hline 13- Seniors sometimes cry when there's & True & 34.1 & & & 54.9 & & \\
\hline nothing to worry about. & False & 65.9 & .34 & .48 & 45.1 & .55 & .50 \\
\hline 14- I think it's ridiculous to treat cats and dogs & True & 71.9 & .72 & .45 & 73.6 & .74 & .44 \\
\hline like people. & False & 28.1 & & .45 & 26.4 & .74 & \\
\hline 15- It makes me angry when a friend always & True & 58.5 & .59 & .49 & 42.9 & .43 & .50 \\
\hline asks for help from the teacher & False & 41.5 & .59 & .49 & 57.1 & .43 & .00 \\
\hline 16- Children without friends probably never & True & 84.4 & .84 & .36 & 82.4 & .82 & .38 \\
\hline want to have friends. & False & 15.6 & .84 & .36 & 17.6 & .82 & .00 \\
\hline 17- My eyes get watery when I see a girl & True & 58.5 & .59 & .49 & 11.0 & .11 & .31 \\
\hline crying. & False & 41.5 & & & 89.0 & & \\
\hline 18- I find it funny that some people cry while & True & 68.9 & .69 & .46 & 47.3 & .47 & .50 \\
\hline watching a sad movie or reading a sad novel. & False & 31.1 & .69 & .46 & 52.7 & .47 & .00 \\
\hline 19- When my friends have nothing to eat, I can & True & 87.4 & .87 & .33 & 76.9 & .77 & .42 \\
\hline easily eat my cookies while they are nearby. & False & 12.6 & .87 & .33 & 23.1 & .77 & .42 \\
\hline 20- I don't get upset when a friend gets & True & 54.8 & .55 & .50 & 61.5 & .62 & .49 \\
\hline punished for misbehavior. & False & 45.2 & & & 38.5 & & \\
\hline
\end{tabular}

When the genderwise responses given to the items are examined, it is seen that girls are more empathetic than boys. It is also seen that the empathetic behaviors of the child athletes towards their fellow child athletes also change. More than half of the females (\%58.5) marked Item 17 as True while this was $11.0 \%$ in male participants. When the "girl" (in Item 17) was changed into "boy" in the statement (Item 5), $\% 43.7$ of the females marked it as True while it was $44.0 \%$ in males. $34.1 \%$ of the girls marked Item 13 as True while this percentage went up to $54.9 \%$ in boys.

Table 3. Results of Independent Samples T-test on Empathy Levels of Child Athletes According to Gender Variable

\begin{tabular}{ccccccccc} 
& & $\mathrm{N}$ & $\mathrm{M}$. & $\mathrm{SD}$ & $\mathrm{df}$ & $\mathrm{t}$ & $\mathrm{p}$ \\
\multirow{2}{*}{ EMPATHY SCALE FOR CHILDREN } & Female & 135 & .67 & .17 & & 224 & 6.193 & .00
\end{tabular}

When Table 3 is examined, it is seen that the empathy levels of child athletes differed according to gender and this difference was statistically significant in favor of females. $(\mathrm{p}=.00)$.

\section{DISCUSSION \& CONCLUSION}

The studies on the relationship between empathy and gender revealed that women are more empathetic than men. It is possible to explain this situation according to two theories as social and psychological. For example, according to sociologists, this difference is explained in relation to the social roles that men and women have, while psychoanalysts explain this difference with the emotional capacity women have (8). When the literature was examined, it was concluded that the relationship between affective and cognitive empathy and gender was investigated in women aged between 12 and 18 years, and women were more empathetic than men (2). In another study, Klein and Hodges found that women were more empathetic than men in their study of gender differences (16). In studies of sports and empathy, it is seen that there was differentiation in regard to gender. Studies show that female sportspeople are more empathetic than male sportspeople. Sezen-Balçıkanlı and Yıldıran's (2018) study on elite inline hockey players showed that empathetic skills are higher in women than men. In the study conducted by Sezen-Balçıkanlı and Sezen (2019) on young hockey players, the difference between the genders was in favor of women. In Aktaş and Sezen-Balçıkanlı's study (2018), which examined the relationship between physical education 
teachers' empathy and social problem solving skills, it was seen that women had more empathetic thoughts than men. Similarly, the studies on empathy in children showed that girls are more empathetic than boys $(4,7,11)$.

When the findings of the study were examined, it is seen that there was a difference between the genders in sports people and this difference was in favor of girls (Table 3). However, it is also known that empathy education and empathetic model for children can reduce this gap between genders (9). The findings show that children take a more empathetic attitude towards children of the same gender. For instance, more than half of the girls (58.5\%) marked the statement that "My eyes get watery when I see a girl crying" as True while this was $11.0 \%$ in males. When the "girl" was changed into "boy" in the statement (Item 5), the percentage went down to $43.7 \%$ in girls and went up to $44.0 \%$ in boys. Social roles are thought to be effective in the emergence of these ratios. Another item included the behavior that "I feel

\section{REFERENCES}

1. Akkoyun F. Empathetic tendency and moral judgment. Journal of Psychology, 1987; 21(6): 91-97.

2. Ang RP, Goh DH. Cyberbullying among adolescents: The role of affective and cognitive empathy, and gender. Child Psychiatry \& Human Development, 2010; 41(4): 387-397.

3. Bryant B. An index of empathy for children and adolescents. Child Development, 1982; 53: 413-425.

4. Cotton K. Developing empathy in children and youth. Northwest Regional Educational Laboratory, 1992:2-4.

5. Davis HM. Measuring individual differences in empathy: Evidence for a multidimensional approach. Journal of Personality and Social Sychology, 1983; 44(1): 113-126.

6. Duquin MB, Schroeder K. Power, empathy, and moral conflict in sport. Peace and Conflict, 1996; 2(4): 351-367.

7. Eisenberg N, Spinrad TL, Sadovsky A. Empathy-related responding in children. Handbook of Moral Development, 2006: 517-549.

8. Eisenberg N, Strayer J (Eds.). Empathy and its development. CUP Archive, 1990:60-68.

9. Eisenberg-Berg N, Mussen P. Empathy and moral development in adolescence. Developmental Psychology, 1978; 14(2): 185-186.

10. Klein KJK, Hodges SD. Gender differences, motivation, and empathetic accuracy: When it pays to understand. Personality and Social Psychology Bulletin, 2001; 27(6): 720-730.

11. Landazabal MG. A comparative analysis of empathy in childhood and adolescence: Gender differences and associated socio-emotional variables. International Journal of Psychology and Psychological Therapy, 2009; 9(2): 217-235.

12. Lorimer R, Jowett S. Empathetic accuracy, meta-perspective, and satisfaction in the coach-athlete relationship. Journal of Applied Sport Psychology, 2009; 21(2): 201-212.

13. Rogers CR. Empathetic: An unappreciated way of being. The Counseling Psychologist, 1975; 5(2), 2-10.

14. Sezen-Balçıkanlı G, Sezen M. Professional sports and empathy: relationship between professional futsal players' tendency toward empathy and fouls. Physical Culture and Sport Studies and Research, 2017; 73(1): 27-35. like crying when I see a boy hurt his knee while playing" (Item 12). This behavior was marked as True by $31.9 \%$ of the girls and 28.6 of the boys. Item 17, stating that "My eyes get watery when I see a girl crying" was marked as True by $58.5 \%$ of the girls and $11 \%$ of the boys. While evaluating the effect of gender in these results, it is thought that sport also has an effect on these low percentages. As a matter of fact, research shows that competition affects empathetic skills negatively $(22,19,21,16,17,20,14,18,15)$.

As a result, the activities aiming to improve the sportspeople's taking roles and perspectives along with empathetic thinking skills should be included in the process of creating empathetic people thus empathetic sensitivity should be increased. In particular, coaches whose target audience are children should take an empathetic attitude towards coaches and athletes, model them, solve problems from an empathetic point of view and support empathy education through sports.

15. Sezen-Balçıkanlı G, Sezen M. The relationship between empathy and antisocial-prosocial behaviours in youth field hockey players. International Journal of Learning and Change, 2019; 11(1): 57-65.

16. Sezen-Balçıkanlı G, Yıldıran İ. Professional players' sportsmanship orientations and empathetic tendency levels. Spormetre Journal of Physical Education and Sport Sciences, 2011; 9(2): 49-56.

17. Sezen-Balçıkanlı G, Yıldıran İ. Sportspersonship orientation and empathy: a study of professional football players. Journal of Physical Education and Sport, 2012; 12(1): 18.

18. Sezen-Balçıkanlı G, Yıldıran İ. The relationship between empathetic skill and prosocial behavior in elite inline hockey players. Gazi Journal of Physical Education and Sport Sciences, 2018; 23(1): 1-8.

19. Sezen-Balçıkanlı G. Fair play and empathy: A research study with student teachers. Journal of US-China Public Administration, 2009a; 6(4): 79-84.

20. Sezen-Balçıkanlı G. Fair play in professional sports: Sportspersonship orientations of futsal players. FairPlay, Revista de Filosofia, Ética y Derecho del Deporte, 2014; 2(1): 3349.

21. Sezen-Balçıkanlı G. The relationship between professional players' fair play behavior and empathetic tendency levels. Unpublished Doctoral Dissertation, Gazi University, 2009b, Ankara.

22. Shields LL, D Bredemeier JB, Brenda JL. Chracter development and physical activity. USA: Human Kinetics, 1994:90-93.

23. Yüksel A. The effect of empathy education program on the empathetic skills of primary school students. Uludağ University Journal of Faculty of Education, 2004; 17(2): 341-354. 